\title{
Context processing during irony comprehension in right-frontal brain-damaged
}

\section{individuals}

Maud Champagne-Lavau ${ }^{1}$, Natacha Cordonier ${ }^{2}$, Anne Bellmann $^{3}$, Marion Fossard ${ }^{2}$

1. Aix-Marseille Univ, CNRS, LPL, Aix-en-Provence, France

2. Faculté des lettres et sciences humaines, Institut des sciences du langage et de la communication, Université de Neuchâtel, Neuchâtel, Suisse

3. Clinique Romande de réadaptation, Sion, Suisse

Manuscript accepted for publication in Clinical Linguistics and Phonetics

Champagne-Lavau, M., Cordonier, N., Bellmann, A. \& Fossard, M. (2018). Context processing during irony comprehension in right frontal brain-damaged individuals. Clinical Linguistics and Phonetics, 32(8), 721-738.

Corresponding author: Maud Champagne-Lavau, Ph.D.

Aix-Marseille Université

LPL, CNRS UMR 7309

5 Av. Pasteur

B.P. 80975

13604 Aix-en-Provence, France

Phone: (33) 0413552707

email: maud.champagne-lavau@univ-amu.fr 


\begin{abstract}
The aim of the present study was to investigate whether the degree of incongruity between contextual information and a target sentence influences the extent to which irony is understood in individuals with right-frontal-hemisphere damage. A psycholinguistic paradigm was used, allowing us to assess whether impairment in irony understanding is likely to be due to insensitivity (i.e. difficulty in capturing or detecting relevant contextual information) to relevant contextual information or to difficulties in integrating contextual information. Twenty individuals with right-frontal hemisphere damage (RHD) and twenty healthy control (HC) participants were tested on their understanding of a speaker's ironic intent and their executive functions. The main results revealed that individuals with RHD exhibit different patterns of performance, some of them being able to understand irony while in others this ability was impaired. The present study gives support to the hypothesis that difficulties in adequately using contextual information may account for pragmatic impairment of individuals with RHD. More importantly, the results suggested that these difficulties are related to a lack of sensitivity to contextual information instead of difficulty integrating it along with the ironic utterance. A subgroup of individuals with RHD processed the speaker's utterance without any reference to contextual information, which led them to a literal interpretation of the utterance.
\end{abstract}

Keywords: Pragmatics, irony, context processing, individuals with right-hemispheredamaged 


\section{Introduction}

People with right-hemisphere damage (RHD) have been shown to experience pragmatic impairments typically affecting the processing of non-literal language (e.g. irony, sarcasm, metaphor, non-conventional indirect request) (see Joanette, Champagne-Lavau, Kahlaoui \& Ska, 2007; Monetta \& Champagne-Lavau, 2009; Myers, 1998 for a review; Van Lancker \& Kempler, 1987). Non-literal utterances require the ability to process the speaker's utterance beyond its literal meaning in order to allow one to grasp the speaker's intention by reference to the contextual information (Grice, 1975; Searle, 1969). Ironic utterances are traditionally defined as utterances expressing something other than the literal meaning and most commonly the opposite of what has been said by the speaker, while sarcasm is caustic and directed against someone (Gibbs, 1986).

Regarding the comprehension of irony and sarcasm, individuals with RHD have been found to exhibit difficulty distinguishing lies from sarcasm and managing counterfactual information (Champagne, Virbel, Nespoulous \& Joanette, 2003; Cheang \& Pell, 2006; Kaplan, Brownell, Jacobs \& Gardner, 1990; McDonald 1999; McDonald 2000a, McDonald \& Pearce, 1996; Tompkins \& Mateer, 1985; Winner, Brownell, Happé, Blum \& Pinkus, 1998). They also have trouble using knowledge about the affective relationship between the speakers to make inferences on sarcasm (Cheang \& Pell, 2006; Kaplan et al., 1990). They tend to interpret inconsistent comments as jokes or lies instead of sarcasm (See McDonald 2000b for a review). Other studies showed that participants with RHD were less likely to use contextual information such as the speaker's tone of voice or the speaker's mood, which indicate that the speaker's utterance is sarcastic (Brownell, Carroll, Rehak \& Wingfield, 1992; McDonald \& Pearce, 1996; Tompkins \& Mateer, 1985). The present study aimed to give insight into the specific mechanisms underlying impairments in irony understanding in individuals with RHD by studying underlying cognitive processes, such as context processing involved in irony comprehension.

Following the distinctive role of the left and right hemispheres for the local versus global processing of visuospatial information (Delis, Kiefner \& Fridlund, 1988), it has been suggested that weak coherence might account for the difficulties individuals with RHD experience using contextual information to derive non-literal meaning (Martin \& McDonald, 2003). In other words, the right hemisphere would play a specific role in the holistic, global processing of the utterances, creating coherence and integrating different sources of contextual information to produce a meaningful whole (Martin \& McDonald, 2003). As pragmatics refers to the use of language in context and thus, depends on the integration of 
different kind of contextual information (e.g. the situational context, knowledge on the speaker and also encyclopaedic knowledge on the world) a holistic processing of the utterances taking into account this contextual information would lead to the non-literal interpretation of the utterance. By contrast, analytic processing based on words meaning of the sentence would only allow for a literal interpretation of the utterance (Cornejo, Simonetti, Aldunate, Ibanez, Lopez \& Melloni, 2007).

According to the results reviewed above, individuals with RHD seem to be impaired in their use of various contextual information (e.g. information on the speaker, the situational context) when understanding irony or sarcasm, which has been generally described either as an inappropriate contextual use of language or an inability to integrate information across sentence boundaries (Brownell, Griffin, Winner, Friedman \& Happé, 2000; Martin \& McDonald, 2003; Monetta \& Champagne-Lavau, 2009). To our knowledge, no study has shown whether the inappropriate contextual use of language (i.e. comprehension and production) exhibited by individuals with RHD comes from a lack of sensitivity to context (i.e. difficulty in capturing or detecting relevant contextual information) or from an inability to integrate contextual information (correctly detected) when understanding non-literal language. To assess this distinction between sensitivity and integration, we focused on the comprehension of irony, using a paradigm which enabled us to manipulate the level of contextual incongruity. It has been demonstrated that the degree of incongruity between situational context and speaker's utterance cues the extent to which ironic intent is perceived (Ivanko \& Pexman, 2003). This means that healthy people better understand ironic utterances presented in a context with strong incongruity between events and the literal meaning of the speaker's utterance than in a context with weak incongruity (Champagne-Lavau et al., 2012; Ivanko \& Pexman, 2003). For instance, if a speaker says to me "you are a wonderful cook", the utterance might be interpreted as a literal compliment (i.e., you really are a good cook) or as an ironic insult (i.e., you are a terrible cook). If the meal was burned, the event could be perceived as even more negative than if the meal lacked salt. The first contextual sentence (the meal was burned) contrasts more sharply with the positive literal meaning of the utterance "You are a wonderful cook" than the second contextual sentence (the meal lacked salt) does, inducing then a strong contextual incongruity and a better understanding of the utterance as being ironic. By contrast, the contextual incongruity is weaker when the utterance "you are a wonderful cook" appears after the second contextual sentence (i.e. the meal lacked salt) than after the first one (i.e. the meal was burned) leading to a potential ambiguity, the speaker's utterance being possibly understood as ironic or non ironic. This finding was used 
in the present study to assess the respective roles of insensitivity versus impaired integration of contextual information in irony understanding by individuals with RHD. Indeed, following the result from Ivanko \& Pexman (2003), people are expected to be influenced by the level of incongruity between the context and the speaker's utterance when understanding irony. They are thus expected to interpret the speaker's utterance as well in strong incongruity context conditions as in no incongruity context conditions (this last condition leading to a literal interpretation). They are also expected to better understand ironic utterances in the strong incongruity context conditions than in the weak incongruity context conditions. By contrast, individuals with RHD having difficulty understanding ironic utterances should show worse performances in the strong and weak incongruity context conditions than in the no incongruity context conditions. Such difficulty to understand ironic utterances could come from either a lack of sensitivity to contextual information (i.e. difficulty in capturing or detecting relevant contextual information) or to difficulty to integrate contextual information which should be respectively evidenced with the following patterns of performances. On one hand, a lack of sensitivity to contextual information in irony understanding should arise from an absence of difference of performance between the strong (i.e. the meal was burned) and the weak incongruity context (i.e. the meal lacked salt) conditions since the relevant contextual information allowing the manipulation of the incongruity strength would not have been decoded. On the other hand, difficulty integrating contextual information in irony understanding should be manifest in a better understanding of irony in the strong incongruity context condition than in the weak incongruity context condition, individuals with RHD being able to detect, in this case, the relevant contextual information cueing the incongruity strength as healthy people are.

One should not forget the known heterogeneity existing amongst individuals with RHD regarding their communication impairments including pragmatics. Indeed, not all individuals with RHD present such disorders and different patterns of deficits exist among individuals with RHD (Blake, Duffy, Myers \& Tompkins, 2002; Champagne-Lavau \& Joanette, 2009; Cote, Payer, Giroux Joanette, 2007; Joanette, Goulet \& Daoust, 1991). Most authors estimate the prevalence of the disorders at 50\% (Benton \& Bryan 1996; Champagne-Lavau \& Joanette 2009; Joanette et al. 1991). Amongst patients with RHD, those who had frontal lesions were shown to be the most likely to present a deficit affecting non-literal language (ChampagneLavau \& Joanette, 2009; Papagno, Curti, Rizzo, Crippa, \& Colombo, 2006; Shamay-Tsoory, Tomer, \& Aharon-Peretz, 2005; Shammi \& Stuss, 1999). Thus, given the diversity of patterns after right-hemisphere damage, the present study included people with right-hemisphere 
lesions in frontal areas, those lesions extended into other areas for some individuals. Furthermore, performances of participants with RHD were studied using a cluster analysis based on their performances in irony comprehension. This analysis led to a classification of the patients with RHD into subgroups enabling us to characterize different profiles among them.

The aim of the present study was to investigate whether the degree of contextual incongruity influences the extent to which irony is understood in individuals with right-frontal-hemisphere damage. The use of the paradigm of Ivanko and Pexman (2003) allowed us to assess whether impairment in irony understanding is likely to be due to insensitivity to relevant contextual information or to difficulties to integrate contextual information. To this aim we measured the percentage of correct interpretation of the speaker's utterance in different context conditions (i.e. ironic interpretation in the strong and weak incongruity context conditions, literal interpretation in the no incongruity context condition). We hypothesized that difficulty in using contextual data that cue the speaker's ironic intent would have an impact on irony understanding in participants with RHD. More precisely, healthy control participants were expected to perform as well as in the strong and the no incongruity context conditions. They were also expected to better understand ironic utterances in the strong incongruity context conditions than in the weak incongruity context conditions. By contrast, if participants with RHD impaired in irony understanding had a lack of sensitivity to relevant contextual information they were expected to show the same pattern of performances in the strong and the weak incongruity context conditions associated to a lower performance in the strong incongruity than in the no incongruity context conditions. However, if they had difficulties to integrate contextual information, they were expected to show a better irony understanding in the strong incongruity context conditions than in the weak incongruity context conditions associated with a lower performance in the strong incongruity context conditions than in the no incongruity context conditions.

\section{Methods}

\section{Participants}

The sample consisted of 40 participants: twenty individuals with right-frontal-hemisphere damage (RHD) and twenty healthy control (HC) participants matched with the participants with RHD for age and educational level (cf. Table 2 for the demographic data). All participants with RHD were recruited from the Clinique Romande de Réadaptation in Sion, Switzerland. HC participants were recruited in the local community. The two groups did not 
significantly differ with regard to age $(t(38)=.198, p>.05)$ and educational level $(t(38)=$ $.056, p>.05)$. All participants with RHD had unilateral right-hemisphere damage of vascular origin (ischemic or hemorrhagic) as documented by a CT scan (cf. Table 1). Only patients with at least one right-frontal lesion were included in the study. The amount of time between onset of stroke and the time of testing ranged from 8 to 276 months. All participants were right-handed and native French speakers with no previous psychiatric or alcoholic history. Healthy control participants have no previous neurological history.

Written consent forms were obtained from all participants, according to guidelines for ethic questions in research of the Swiss Society of Psychology (http://www.sspsgp.ch/02_SSP/commission_f.html).

\section{Insert table 1 about here}

\section{Measures}

\section{Neuropsychological measures}

As Champagne-Lavau \& Joanette (2009) found that inhibition versus flexibility could be involved in different patterns of pragmatic performances, executive functions drawing on inhibition and flexibility were also assessed with standardized neuropsychological tests (Spreen \& Strauss, 1998). Inhibition was assessed with the Stroop test (Stroop, 1935) and the French version of the Hayling test (Rouleau, 1998). The Stroop test assessed the ability to maintain a goal in mind and suppress a habitual response in favor of a less familiar one while the Hayling test measures the ability to inhibit a semantically constrained response (Spreen \& Strauss, 1998). The Hayling test is composed of two parts, the automatic condition involving the initiation of a semantically supported automatic response and the inhibition condition requiring the inhibition of the activated word and its semantic associates. In the automatic condition, participants were asked to rapidly complete predictable sentences (Most cats see very well at...) with the expected word, while in the inhibition condition, they were asked to do it with a word that fills the gap, does not make sense and is unrelated to the expected ending. For the Stroop test, the time recorded in the interference condition was reported as a measure of inhibition while two scores (automatic and inhibition conditions) taking into account response latencies and response accuracy were calculated according to Burgess \& Shallice (1997) for the Hayling test. The ability to switch from one strategy to another, i.e. flexibility, was assessed with the Trail-Making test (Reitan \& Wolfson, 1993). The completion times in condition B and A were recorded and a time score (Trail B/Trail A) was 
calculated as a measure of flexibility. The number of categories and the percentage of perseveration of the Wisconsin Card Sorting Test (WCST) (Heaton, 1981) were also recorded as measures of flexibility. Participants were also evaluated on their working memory to exclude any impairment that could have an impact on the irony task. The Digit Span subtest (forward and backward) from the WAIS-III (Wechsler, 1981) was used to assess working memory.

\section{Understanding of irony}

In the present study, we replicated the methods of Ivanko and Pexman (2003) adapted in French by Champagne-Lavau et al. (2012). Thus, twelve stories by Champagne-Lavau et al. (2012) adapted in French from Ivanko and Pexman (2003) and controlled for familiarity and plausibility were used in the present study to assess irony understanding. To assess how context manipulation influenced participants' irony understanding, context was manipulated according to the degree of context incongruity (strong incongruity, weak incongruity, no incongruity) between contextual information and target sentence (cf. Appendix for example). Thus, the 12 stories were distributed in three context conditions intended to trigger either literal meaning (no incongruity) or ironic meaning (strong incongruity, weak incongruity) of the target sentence. Each target sentence (e.g. Christine is a clever student) appeared in each context condition across 3 versions of each stimulus $(12 \times 3=36$ stimuli). Contexts were presented in random order. To control for prosody and memory effect, stimuli were presented on a sheet of paper. Participants were asked to read each of these 36 stimuli, and then answer the following question: "What does X (the speaker) really mean?" to assess their speaker ironic intent understanding. Then a control question was asked on contextual information (e.g. Did Christine receive $100 \%$ on her mathematics exam?).

Scoring. Answers to each control question were scored 1 if correct and 0 if incorrect. Half of the correct answers were "yes" while the other half were "no". Participants provided a verbal answer to the question on irony understanding and the experimenter wrote down the answer word for word. Answers were scored with a binary score in the same way as in ChampagneLavau et al. (2012). When participants incorrectly interpreted the utterance presented in the strong or the weak incongruity context conditions as literal, their answer was scored 0 . In case of a literal interpretation participants gave a paraphrase of the utterance. For example, for the sentence "Marie is a fast runner" uttered after a strong or a weak incongruity context (meaning that Mary is not a fast runner), some participants answered that the speaker meant that Mary runs fast. This answer was scored 0 . When participants correctly interpreted the 
utterance presented in the strong or the weak incongruity context conditions as ironic, their answer was scored 1. In these cases participants said that the speaker was mocking Marie, for example, or they explicitly said that the speaker meant the opposite or something different from what he/she said. All the data were scored by a co-author (NC) and a random sample of the data (30\% of the data, 432 responses) was scored by a research assistant blind to the type of participants tested. The inter-rater reliability was $98.37 \%$ with a Cohen's Kappa $\mathrm{k}=.90 ; p$ $<.0001$.

All participants were tested individually by one experimenter over one session in a quiet room.

\section{Data analysis}

Unpaired $t$-tests were used to explore group differences on the different neuropsychological variables. To determine group differences in the irony task a 2 group (RHD, HC) x 3 context (no incongruity, strong incongruity, weak incongruity) repeated-measures ANOVA was performed on the percentage of correct responses to the different types of question: open question on speaker ironic intent and control question.

A hierarchical cluster analysis (Ward's method) was undertaken according to individuals with RHD performance on the task assessing understanding of ironic intent, to characterize different profiles among them. Ward's method is a minimum distance hierarchical method which calculates the sum of squared Euclidean distances from each case in a cluster to the mean of all variables. This method minimizes the sum of squares of any pair of clusters to be formed at a given step. This cluster analysis was only based on individuals with RHD performances on the open question on the speaker's ironic intent in the three context conditions. Measures of effect size were calculated for each effect of interest by providing the partial eta-squared for ANOVAs and the Cohen's $d$ for t-test. The alpha level was set at $p<$ 0.05 for all the analyses.

\section{Results}

\section{Group comparison on neuropsychological measures}

Significant differences between the RHD and HC groups were found on the Trail B $(t(38)=$ 2.819, $p<0.010$; Cohen's $d=0.89)$, and the Hayling test (inhibition) $(t(38)=-2.912, p<$ 0.006; Cohen's $d=0.92$ ). Thus, the RHD group performed significantly worse than the HC group on the Hayling test that evaluates verbal inhibition (cf. Table 2). 


\section{Group comparison on irony understanding}

The 2 x 3 ANOVA on the percentage of correct responses to the question on speaker's ironic intent revealed a main effect of context $\left(F(2,76)=17.833, p<0.0001 ; \eta_{\mathrm{p}}{ }^{2}=0.319\right)$ with a significantly higher number of errors in the weak incongruity context condition than in the no incongruity context condition $(p<0.0001)$ and than in the strong incongruity context condition $(p<0.0001)$. The number of errors was also significantly higher in the strong incongruity context condition than in the no incongruity context condition $(p<.029)$. A main effect of group $\left(F(1,38)=10.933, p<0.008 ; \eta_{\mathrm{p}}{ }^{2}=0.223\right)$ was also found, showing that participants with RHD made more errors than healthy control participants. The group $x$ context interaction was significant $\left(F(2,76)=5.304, p<0.007 ; \eta_{\mathrm{p}}{ }^{2}=0.122\right)$. This interaction was decomposed according to group. The RHD group made more errors in answering questions on speaker intent in the weak incongruity context condition than in both the no incongruity context condition $(p<0.001)$ and the strong incongruity context condition $(p<$ 0.0001). They also made more errors in answering questions in the strong incongruity context condition than in the no incongruity context condition $(p<0.001)$. In the HC group, there was no difference between the strong incongruity and no incongruity contexts $(p>0.05)$. However, like participants with RHD, healthy control participants made more errors in answering questions on speaker intent in the weak incongruity context condition than in both the no incongruity context condition $(p<0.05)$ and the strong incongruity context condition $(p<0.0001)$ (cf. Table 3).

\section{Insert table 3 about here}

The $2 \times 3$ repeated-measures ANOVA on the percentage of correct responses to the control question on contextual information revealed no main effect of the type of context $(F(2,76)=$ 1.303, $\left.p>0.05 ; \eta_{\mathrm{p}}{ }^{2}=0.033\right)$ and no main effect of group $\left(F(1,38)=0.098, p>0.05 ; \eta_{\mathrm{p}}{ }^{2}=\right.$ $0.033)$. The group $x$ context interaction was not significant $\left(F(2,76)=0.716, p>0.05 ; \eta_{\mathrm{p}}{ }^{2}=\right.$ 0.018) (cf. Table 3). 
Overall, these results showed that participants with RHD made more errors in answering questions on speaker's ironic intent in the strong and weak incongruity context conditions while they performed like healthy control participants in the no incongruity context condition. As predicted, healthy control participants made the same number of errors in the strong incongruity and no incongruity context conditions, in contrast to participants with RHD, meaning that they had correctly understood ironic utterances while the RHD group was not as accurate at interpreting irony. However, participants with RHD performed as healthy control participants when answering the question on contextual information.

\section{Different patterns of RHD performances}

The hierarchical cluster analysis undertaken according to RHD performances on the open question on the speaker's ironic intent in the three context conditions revealed two clusters (cf. Figure 1) suggesting two patterns of performance: the RHD-U group contained 14 participants with RHD unimpaired on the open question on the speaker's ironic intent, while the RHD-I contained 6 participants with RHD who showed impairment on the open question on the speaker's ironic intent.

\section{Insert Figure 1 about here}

Given the small sample size of each RHD subgroup, non parametric tests were performed to explore group differences on the neuropsychological variables and the irony task (Howell, 2008). Non parametric (Kruskal-Wallis) analyses were performed on age, education, time post-onset and neuropsychological data to compare the three groups (RHD-I, RHD-U, HC). When a difference was found, a post hoc Mann-Whitney test was performed. The results revealed significant differences between groups on the Trail B $(p<0.005)$ and on the Hayling (inhibition) $(p<0.03)$ meaning that RHD-U participants showed worse performances than healthy control participants on the Trail B (Mann-Whitney: $U=52, p<0.002$ ) and the Hayling (inhibition) $(U=82.5, p<0.041)$. Post hoc Mann-Whitney tests also revealed that RHD-I participants showed worse performances than healthy control participants on the Hayling (inhibition) $(U=24, p<0.026)$. Comparison between RHD-I and RHD-U participants only revealed a difference that tended to be significant on the time post-onset (Mann-Whitney: $U=19, p=0.058$ ) (cf. Table 4). 
Non parametric (Friedman test) analyses were conducted on the irony data to compare the performances obtained in the three context conditions (no incongruity, strong incongruity, weak incongruity) by each group (RHD-I, RHD-U, HC). When a difference was found, a Wilcoxon test was performed. The Friedman analysis performed on the percentage of correct responses to the question on speaker's ironic intent in the RHD-I group revealed a significant difference between the context conditions $\left(\chi^{2}=11.143, \mathrm{df}=2, p<0.004\right)$ meaning that RHD-I participants made more errors in answering questions on speaker intent in the weak incongruity context condition than in the no incongruity context condition (Wilcoxon test: $Z=$ -2.214, $p<0.027)$. They also made more errors in answering questions in the strong incongruity context condition than in the no incongruity context condition (Wilcoxon test: $Z=$ $-2.214, p<0.027)$. However, there was no difference between the strong incongruity context condition and the weak incongruity context condition (Wilcoxon test: $Z=-1.604, p>0.05$ ). In the RHD-U subgroup, the Friedman analysis revealed a significant difference between the context conditions $\left(\chi^{2}=12.333, \mathrm{df}=2, p<0.002\right)$ The Wilcoxon subsequent tests showed that there was no difference between the strong incongruity and no incongruity context condition $(Z=-.516, p>0.05)$. However, RHD-U participants made more errors in answering questions on speaker intent in the weak incongruity context condition than in the no incongruity context condition $(Z=-1.992, p=0.046)$ and the strong incongruity context condition $(Z=-2.522, p$ $<0.012)$. Results in the HC group were similar to those of the RHD-U subgroup. The Friedman analysis revealed a significant difference between the context conditions $\left(\chi^{2}=\right.$ 27.254, $\mathrm{df}=2, p<0.0001)$. The Wilcoxon tests showed that there was no difference between the strong incongruity and no incongruity contexts $(Z=-1.081, p>0.05)$. However, HC participants made more errors in answering questions on speaker intent in the weak incongruity context condition than in the no incongruity context condition $(Z=-3.342, \mathrm{p}>$ 0.001 ) and the strong incongruity context condition $(Z=-3.768, p<0.0001)$ (cf. Figure 2, and Boxplots in appendix).

\section{Insert Figure 2 about here}

The Friedman analyses performed on the percentage of correct responses to the control question on contextual information revealed no significant difference between the context conditions in the RHD-I $\left(\chi^{2}=4.308, \mathrm{df}=2, p>0.05\right)$ and HC groups $\left(\chi^{2}=0.054, \mathrm{df}=2, \mathrm{p}>\right.$ 
0.05) while a significant difference was found between the context conditions for the RHD-U group $\left(\chi^{2}=6.25\right.$, df $\left.=2, p=0.044\right)$. However, the Wilcoxon subsequent tests showed that there was no difference between the strong incongruity and the no incongruity context condition $(Z=-0.447, p>0.05)$, between the weak incongruity context condition and the no incongruity context condition $(Z=-1.318, \mathrm{p}>0.05)$ and between the weak incongruity context condition and the strong incongruity context condition $(Z=-1.897, \mathrm{p}>0.05)$ (cf. Figure 3).

\section{Insert Figure 3 about here}

To sum up, these results showed that, in contrast to HC and RHD-U participants, RHD-I participants exhibited the same number of errors in the strong and weak incongruity context conditions. They also made more errors in answering questions on speaker's ironic intent in the strong incongruity context condition than in the no incongruity context condition. RHD-U participants performed as healthy control participants. For each of these groups, by contrast to the RHD-I group, the number of errors was the same in the strong incongruity and the no incongruity context conditions.

\section{Discussion}

The present study aimed to investigate whether context processing has an impact on irony understanding in individuals with right-frontal lesions. To this aim, a psycholinguistic paradigm was used to show that the degree of contextual incongruity influences the extent to which ironic intent is understood.

The main results showed that, taken as whole, the RHD group committed more errors in the strong incongruity and weak incongruity context conditions while they performed as the HC group in the no incongruity context condition. However, the cluster analysis pointed out that some of the participants with RHD (RHD-U) were able to understand irony as well as the healthy control participants. A subgroup of participants with RHD (RHD-I) did not perform as well as healthy control participants when asked to answer what the speaker really means. Such results confirmed the known heterogeneity found after a right-hemisphere lesion (Blake et al., 2002; Champagne-Lavau \& Joanette, 2009; Joanette et al., 1991). These results are consistent with previous studies showing that understanding of irony and sarcasm may be impaired in individuals with right-hemisphere damage (Champagne et al., 2003; Cheang \& Pell, 2006; Kaplan et al., 1990; Winner et al., 1998). In the present study, neither age nor 
education of the participants with RHD accounted for the different patterns of performance between the RHD-U and RHD-I subgroups. However, the time post-onset tended to differentiate these two subgroups.

\section{Context processing in irony understanding after a right-frontal lesion}

RHD-I participants committed more errors than healthy control participants and RHD-U participants. More importantly, they also made more errors in the strong incongruity context condition than in the no incongruity context condition, reflecting impairment in irony understanding. In contrast to RHD-I participants, no difference was found between the strong incongruity and the no incongruity context conditions in the HC and RHD-U groups, meaning that the strong incongruity condition cues speaker's ironic intent in these two groups. These expected results confirmed previous results in healthy individuals, showing that the greater the incongruity between context and target utterance, the easier it was to understand ironic intent (Champagne-Lavau et al., 2012; Ivanko \& Pexman, 2003). They also confirmed that only some individuals with RHD are able to use contextual information to understand irony.

As expected, a difference was found between the strong incongruity and the weak incongruity conditions in $\mathrm{HC}$ and RHD-U participants revealing sensitivity to changes in contextual information. Interestingly, such a difference was not found in the RHD-I participants. This result suggests that such a lack of sensitivity to the degree of incongruity between context and the speaker's utterance might account for their impairment in irony understanding. Thus, instead of difficulty integrating contextual information when understanding irony, as it was previously suggested (Bihrle, Brownell, Powelson \& Gardner, 1986; Brownell, Potter, Bihrle, \& Gardner, 1986; Kaplan et al., 1990; Martin \& McDonald, 2003), it seems that the RHD-I participants in the present study may have difficulty capturing or detecting the relevant contextual information. These results are in line with the suggestion of Cornejo et al. (2007). Since they were insensitive to the relevant contextual information, RHD-I participants would process the speaker's utterance in a local, analytic way with no reference to the contextual situation leading them to a literal interpretation. Such a pattern of RHD-I performance concurs with the general characterization of individuals with RHD as tending to be literal, responding to the most concrete, superficial aspect of their environment (Brownell et al., 2000; Myers, 2005). However, while previous research (Martin \& McDonald, 2003) postulated that individuals with RHD may have an inability to integrate information as a meaningful whole, leading to a failure in non-literal language understanding, 
the present study suggests a finer description of their difficulties in managing contextual information, implying a lack of sensitivity to relevant contextual information.

The advantage of the paradigm used in the present study is that it enables us to distinguish between two different patterns of performances: 1) lack of sensitivity to relevant contextual information (i.e. difficulty in capturing or detecting relevant contextual information) evidenced by an absence of difference between the strong incongruity and the weak incongruity conditions associated with a difference between the strong incongruity and the no incongruity conditions (RHD-I pattern of performance), 2) preserved sensitivity to the degree of incongruity between context and target utterance but an inability to integrate such information, shown by a difference in performances between the strong incongruity and the weak incongruity conditions associated with a difference between the strong incongruity and the no incongruity conditions (SZ-I pattern of performance described in Champagne-Lavau et al., 2012).

\section{Characteristics of the individuals with RHD with impaired irony understanding.}

Our study suggests a potential account of time post-onset for the different patterns of performance existing in the population with RHD. However, the difference regarding the time post-onset between the RHD-U (90.36 months) and RHD-I (43.5 months) subgroups only tended to be significant $(p=0.058)$. Such tendency to significance should be confirmed with a larger sample to be able to shed light on the possible impact of the time post-onset on the recovery of the ability to understand irony. This point would definitely deserve further investigation.

Regarding executive functioning of the RHD subgroups, a lack of inhibition was evidenced. Both RHD-U and RHD-I participants were impaired on inhibition by comparison to healthy control participants. However, no difference was found between these two RHD subgroups suggesting that a lack of inhibition would not be involved in the pragmatic difficulties showed by the RHD-I participants in the present study. In sum, it seems that an executive dysfunction cannot - alone - account for pragmatic impairments, as it was previously demonstrated (Champagne-Lavau \& Joanette, 2009). For example, McDonald (2000a) showed there was no correlation between pragmatic abilities and executive function tapping into fluency, verbal conceptual abilities and attention.

There were a number of potential shortcomings in the present study which need to be addressed. Detailed information on the lesion site (i.e. precise anatomical site, extent of the lesion) is required to better explore the impact of the lesion on pragmatic impairment. A 
larger sample size is also needed to confirm the possible impact of the time post-onset on the recovery of the ability to understand irony. Individuals with RHD (RHD-I) exhibiting difficulties to understand irony represented only one-third of the whole group. Further research is required to replicate the RHD-I pattern of performance in a larger sample group.

In conclusion, the present study gives support to the hypothesis that difficulties in adequately using contextual information may account for pragmatic impairments of individuals with RHD. More importantly, it highlighted that these difficulties might concern sensitivity to contextual information leading individuals with RHD to a literal interpretation as they process the speaker's utterance without reference to the contextual information. This study also confirms that individuals with RHD may exhibit different patterns of performance, some of them being able to understand irony while others having an impaired ability to understand irony. 
FICHIER AUTEUR

\section{Declaration of interest}

The authors report no declarations of interest 


\section{References}

Burgess, P.W., \& Shallice, T. (1997). The Hayling and Brixton Tests. Bury St. Edmunds, UK: Thames Valley Test Company.

Benton, E., \& Bryan, K. (1996). Rightcerebral hemisphere damage: Incidence of language problems. International Journal of Rehabilitation Research, 19(1), 47-54. doi: 10.1097/00004356-199603000-00005

Bihrle, A. M., Brownell, H. H., Powelson, J. A., \& Gardner, H. (1986). Comprehension of humorous and nonhumorous materials by left and right brain-damaged patients. Brain and Cognition, 5(4), 399-411.

Blake, M.L., Duffy, J.R., Myers, P.S., Tompkins, C.A. (2002) 'Prevalence and patterns of right hemisphere cognitive/communicative deficits: retrospective data from an inpatient rehabilitation unit', Aphasiology, 16(4), 537-47.

Brownell, H. H., Carroll, J. J., Rehak, A., \& Wingfield, A. (1992). The use of pronoun anaphora and speaker mood in the interpretation of conversational utterances by righthemisphere brain-damaged patients. Brain and Language, 43(1), 121-147. doi: $10.1016 / 0093-934 \times(92) 90025-\mathrm{a}$

Brownell, H., Griffin, R., Winner, E., Friedman, O., \& Happé, F. (2000). Cerebral lateralization and theory of mind. In S. Baron-Cohen, Tager-Flusberg, H., \& Cohen, D. (Eds.), Understanding other minds: perspective from developmental cognitive neuroscience (pp. 306-333). Oxford: University Press.

Brownell, H. H., Potter, H. H., Bihrle, A. M., \& Gardner, H. (1986). Inference deficits in right brain-damaged patients. Brain and Language, 27(2), 310-321.

Bryant, G. A., \& Fox Tree, J. E. (2002). Recognizing verbal irony in spontaneous speech. Metaphor and Symbol, 17(2), 99-117.

Champagne-Lavau, M., Charest, A., Anselmo, K., Rodriguez, J. P., \& Blouin, G. (2012). Theory of mind and context processing in schizophrenia: The role of cognitive flexibility. Psychiatry Research, 200(2-3), 184-192. doi: 10.1016/j.psychres.2012.06.011

Champagne-Lavau, M., \& Joanette, Y. (2009). Pragmatics, theory of mind and executive functions after a right-hemisphere lesion: Different patterns of deficits. Journal of Neurolinguistics, 22(5), 413-426. doi: 10.1016/j.jneuroling.2009.02.002

Champagne, M., Virbel, J., Nespoulous, J. L., \& Joanette, Y. (2003). Impact of right hemispheric damage on a hierarchy of complexity evidenced in young normal subjects. Brain and Cognition, 53(2), 152-157. 
Cheang, H. S., \& Pell, M. D. (2006). A study of humour and communicative intention following right hemisphere stroke. Clinical Linguistics \& Phonetics, 20(6), 447-462.

Colston, H. L. (2002). Contrast and assimilation in verbal irony. Journal of Pragmatics, 34, $111-142$

Cornejo, C., Simonetti, F., Aldunate, N., Ibanez, A., Lopez, V., \& Melloni, L. (2007). Electrophysiological evidence of different interpretative strategies in irony comprehension. Journal of Psycholinguistic Research, 36, 411-430. doi: 10.1007/s10936-007-9052-0

Cote, H., Payer, M., Giroux, F., \& Joanette, Y. (2007). Towards a description of clinical communication impairment profiles following right-hemisphere damage. Aphasiology, 21(6-8), 739-749. doi: Doi 10.1080/02687030701192331

Delis, D. C., Kiefner, M. G., \& Fridlund, A. J. (1988). Visuospatial dysfunction following unilateral brain-damage - dissociations in hierarchical and hemispatial analysis. Journal of Clinical and Experimental Neuropsychology, 10(4), 421-431. doi: $10.1080 / 01688638808408250$

Gibbs, R. W. (1986). On the psycholinguistics of sarcasm. Journal of Experimental Psychology-General, 115(1), 3-15.

Grice, H. P. (1975). Logic and Conversation. In P. C. J. L. Morgan (Ed.), Syntax and Semantics: Speech Acts (Vol. 3, pp. 41-58). New York: Academic Press.

Heaton, R. K. (1981). Wisconsin card sorting test: Manual. Odessa, FL: Neuropsychological Assessment Resources.

Howell, D.C. (2008). Méthodes statistiques en sciences humaines. Bruxelles : De Boeck.

Ivanko, S. L., \& Pexman, P. M. (2003). Context incongruity and irony processing. Discourse Processes, 35(3), 241-279.

Joanette, Y., Goulet, P., \& Daoust, H. (1991). Incidence et profils des troubles de la communication verbale chez les cérébrolésés droits. Revue de Neuropsychologie, 1(1), 3 27.

Joanette, Y., Champagne-Lavau, M., Kalhaoui, K., \& Ska, B. (2007). The future of our knowledge of communication impairments following a right-hemisphere lesion. In M.J. Ball, \& J.S. Damico (Eds.), Clinical Aphasiology - Future Directions. Hove: Psychology Press.

Kaplan, J. A., Brownell, H. H., Jacobs, J. R., \& Gardner, H. (1990). The effects of right hemisphere damage on the pragmatic interpretation of conversational remarks. Brain and Language, 38(2), 315-333. 
Martin, I., \& McDonald, S. (2003). Weak coherence, no theory of mind, or executive dysfunction? Solving the puzzle of pragmatic language disorders. Brain and Language, $85(3), 451-466$.

McDonald, S. (1999). Exploring the process of inference generation in sarcasm: A review of normal and clinical studies. Brain and Language, 68(3), 486-506.

McDonald, S. (2000a). Exploring the cognitive basis of right-hemisphere pragmatic language disorders. Brain and Language, 75(1), 82-107. doi: 10.1006/brln.2000.2342

McDonald, S. (2000b). Neuropsychological studies of sarcasm. Metaphor and Symbol, 15(1\&2), 85-98.

McDonald, S., \& Pearce, S. (1996). Clinical insights into pragmatic theory: frontal lobe deficits and sarcasm. Brain and Language, 53, 81-104.

Myers, P.S. (1998) Right Hemisphere Damage: Disorders of Communication and Cognition, San Diego: Singular Publishing.

Papagno, C., Curti, R., Rizzo, S., Crippa, F., \& Colombo, M. R. (2006). Is the right hemisphere involved in idiom comprehension? A neuropsychological study. Neuropsychology, 20(5), 598-606. doi: 10.1037/0894-4105.20.5.598

Regel, S., Coulson, S., \& Gunter, T. C. (2010). The communicative style of a speaker can affect language comprehension? ERP evidence from the comprehension of irony. Brain Research, 1311, 121-135.

Regel, S., Meyer, L., \& Gunter, T. C. (2014). Distinguishing Neurocognitive Processes Reflected by P600 Effects: Evidence from ERPs and Neural Oscillations. PloS One, 9(5).

Reitan, R. M., \& Wolfson, D. (1993). The Halstead-Reitan neuropsychological test battery. Tucson, AZ: Neuropsychology Press.

Rouleau, N. (1998). Étude des processus inhibiteurs de la mémoire de travail dans le vieillissement normal et la démence de type Alzheimer. Unpublished doctoral dissertation, Department of Psychology, Université de Montréal, Montreal.

Searle, J.R. (1969). Speech acts: An essay in the philosophy of language. Cambridge : Cambridge University Press.

Shamay-Tsoory, S. G., Tomer, R., \& Aharon-Peretz, J. (2005). The neuroanatomical basis of understanding sarcasm and its relationship to social cognition. Neuropsychology, 19(3), 288-300. doi: 10.1037/08947-4105.19.3.288

Shammi, P., \& Stuss, D. T. (1999). Humour appreciation: a role of the right frontal lobe. Brain, 122 ( Pt 4), 657-666. 
Spotorno, N., Cheylus, A., Van Der Henst, J.-B., \& Noveck, I. A. (2013). What's behind a P600? Integration Operations during Irony Processing. PloS One, 8(6), e66839.

Spreen, O., \& Strauss, E. (1998). A compendium of neuropsychological tests. New York: Oxford University Press.

Stroop, J. R. (1935) Studies of interference in serial verbal reactions. Journal of Experimental Psychology, 18, 643-662.

Tompkins, C. A., \& Mateer, C. A. (1985). Right hemisphere appreciation of prosodic and linguistic indications of implicit attitude. Brain and Language, 24(2), 185-203. doi: $10.1016 / 0093-934 x(85) 90130-0$

Van Lancker, D. \& Kempler, D. (1987). Comprehension of familiar phrases by left- but not by right-hemisphere damaged patients. Brain and Language, 32, 265-277.

Wechsler, D. (1981). Wechsler Adult Intelligence Scale - Revised. San Antonio, TX: The Psychological Corporation.

Winner, E., Brownell, H., Happe, F., Blum, A., \& Pincus, D. (1998). Distinguishing lies from jokes: theory of mind deficits and discourse interpretation in right hemisphere braindamaged patients. Brain and Language, 62(1), 89-106. 
FICHIER AUTEUR

\section{Appendix}

Sample stimuli

\section{Stimuli with strong contextual incongruity}

Christine and Marie wrote the same math exam. Christine hardly studied and received 20\% on the exam. The next day Marie said to Chantal, "Christine is a clever student".

\section{Stimuli with weak contextual incongruity}

Christine and Marie wrote the same math exam. Christine studied for 2 days and received $60 \%$ on the exam. The next day Marie said to Chantal, "Christine is a clever student".

\section{Stimuli with no contextual incongruity}

Christine and Marie wrote the same math exam. Christine studied for 1 day and received 90\% on the exam. The next day Marie says to Chantal: "Christine is a clever student".

Questions:

$>\quad$ Open question on speaker ironic intent: What did Marie really mean?

$>\quad$ Control question on contextual information: Did Christine receive $100 \%$ on her mathematics exam? 


\section{Boxplots :}

Percentage of correct responses to the question on speaker's ironic intent in the strong incongruity context condition

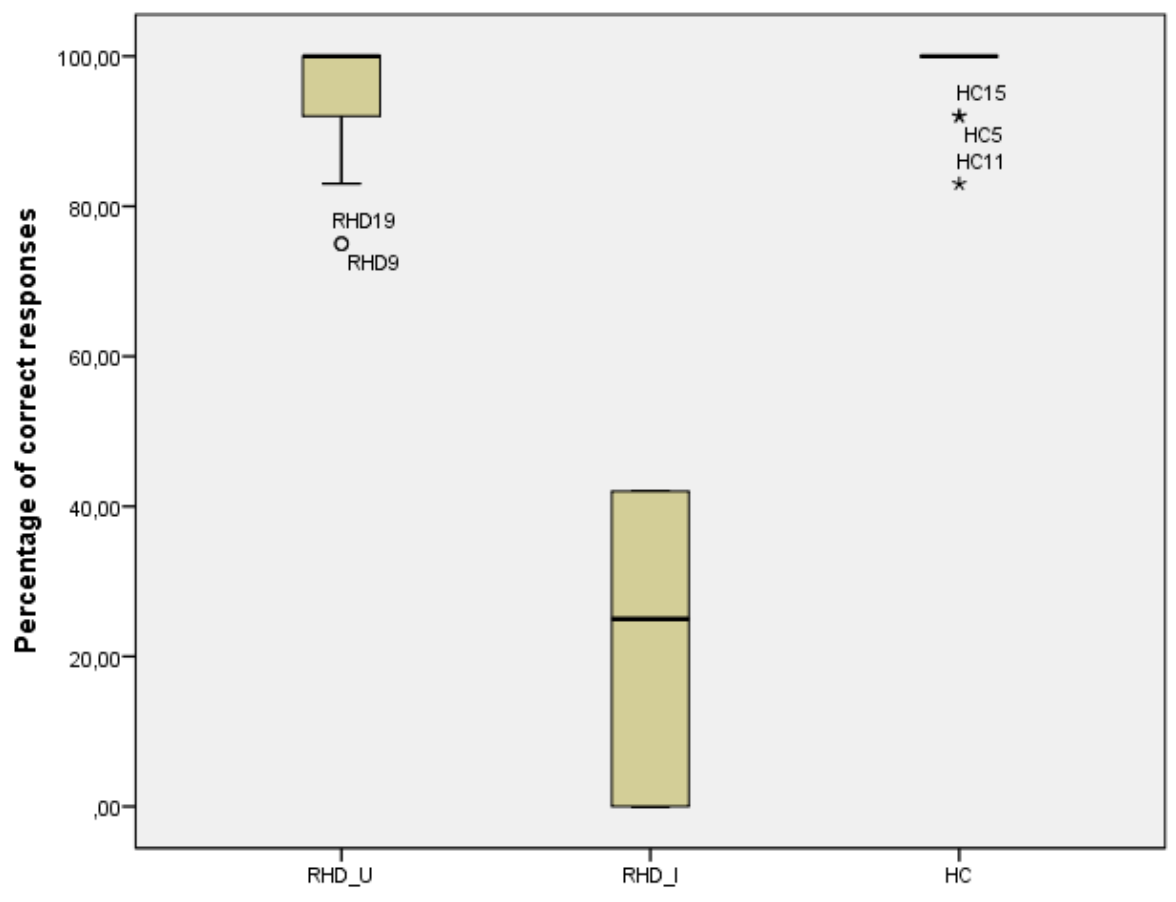

Percentage of correct responses to the question on speaker's ironic intent in the weak incongruity context condition

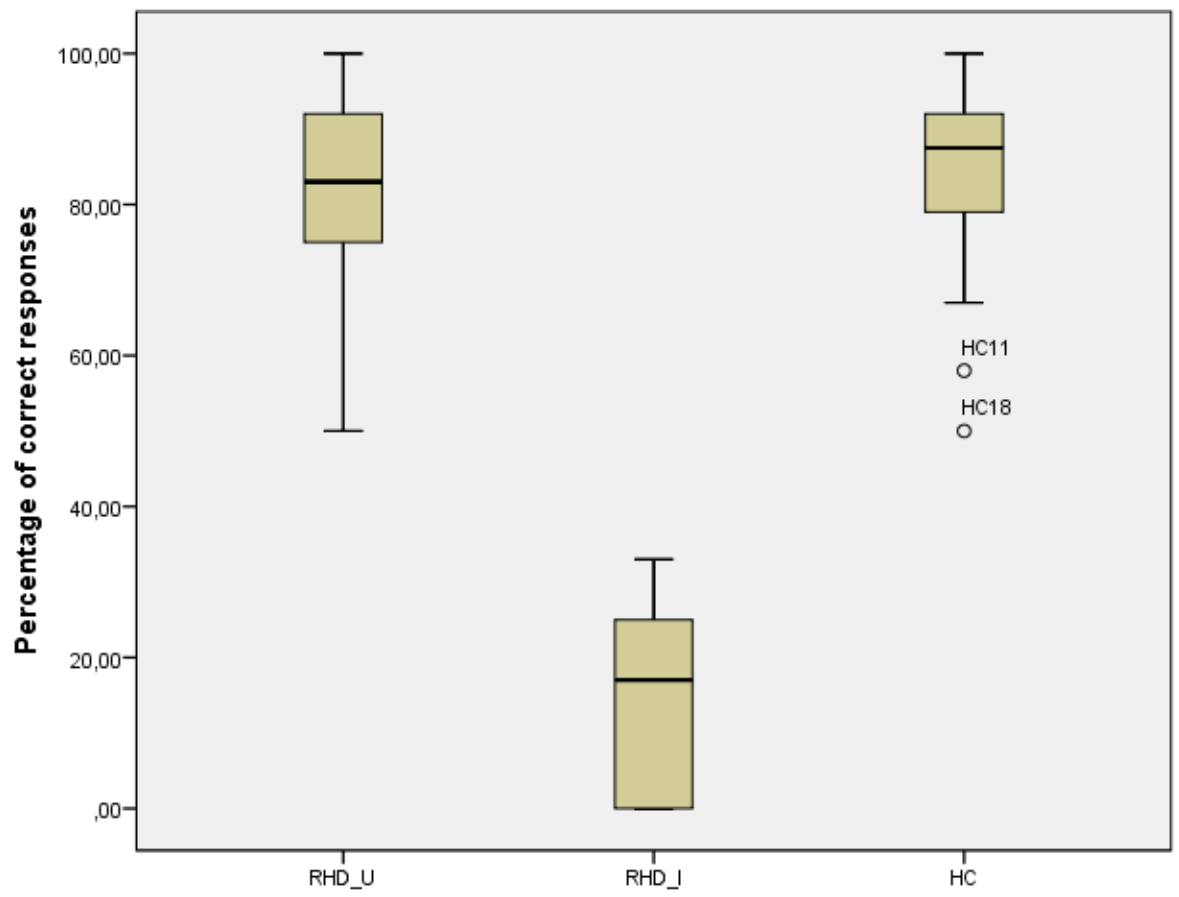


FICHIER AUTEUR

Percentage of correct responses to the question on speaker's ironic intent in the no incongruity context condition

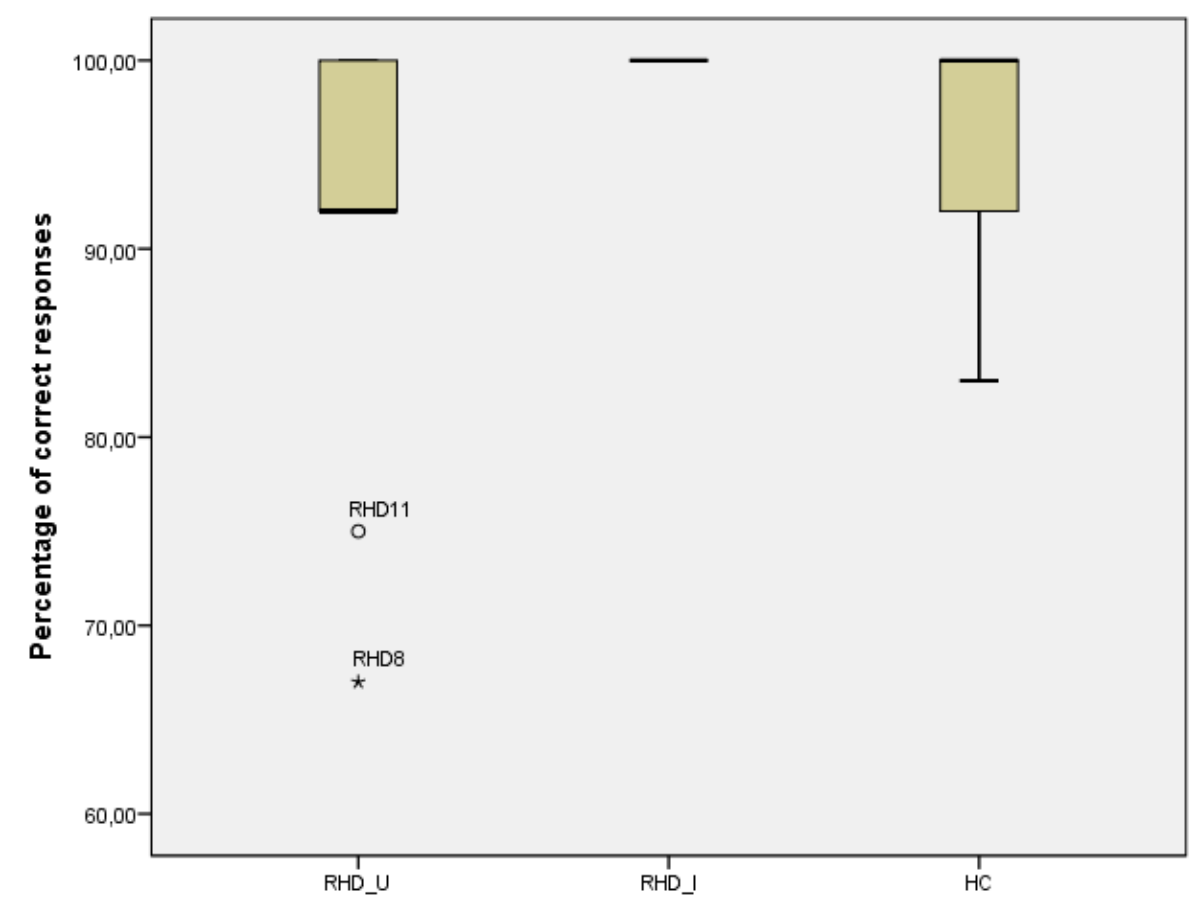


Table 1. Demographic and lesion information

\begin{tabular}{|c|c|c|c|c|c|}
\hline Participants & Gender & Age (years) & $\begin{array}{l}\text { Level of education } \\
\text { (years) }\end{array}$ & Lesion site & $\begin{array}{c}\text { Time post-onset } \\
\text { (months) }\end{array}$ \\
\hline RHD1 & M & 58 & 13 & Right frontal, right middle cerebral artery & 61 \\
\hline RHD2 & $\mathrm{F}$ & 67 & 10 & Right frontal, right middle cerebral artery & 26 \\
\hline RHD3 & M & 75 & 7 & Right frontoparietal & 27 \\
\hline $\mathrm{RHD} 4$ & $\mathrm{~F}$ & 50 & 10 & Right frontal & 200 \\
\hline RHD5 & $\mathrm{F}$ & 48 & 13 & Right fronto-parietal & 146 \\
\hline RHD6 & M & 57 & 19 & Right basal ganglia, right fronto-temporal & 51 \\
\hline RHD7 & M & 64 & 12 & Right fronto-temporal, cerebellum & 15 \\
\hline RHD8 & $\mathrm{F}$ & 71 & 15 & Right frontal & 46 \\
\hline RHD9 & $\mathrm{F}$ & 73 & 15 & Right fronto-temporo-parietal & 35 \\
\hline RHD10 & $\mathrm{F}$ & 78 & 12 & Right frontal & 28 \\
\hline RHD11 & M & 72 & 9 & Right fronto-temporal & 119 \\
\hline RHD12 & $\mathrm{F}$ & 55 & 12 & Right frontal & 13 \\
\hline RHD13 & $\mathrm{F}$ & 52 & 9 & Right frontal, subcortical & 139 \\
\hline RHD14 & $\mathrm{F}$ & 63 & 12 & Right frontal, right basal ganglia, right middle cerebral artery & 8 \\
\hline RHD15 & M & 70 & 13 & Right frontal & 276 \\
\hline RHD16 & M & 70 & 15 & Right fronto-temporo-parietal & 17 \\
\hline RHD17 & M & 60 & 13 & Right fronto-temporo-parietal & 60 \\
\hline RHD18 & $\mathrm{F}$ & 40 & 15 & Right frontal & 188 \\
\hline RHD19 & M & 61 & 9 & Right fronto-parietal, right basal ganglia & 28 \\
\hline RHD20 & M & 56 & 18 & Right frontal & 43 \\
\hline
\end{tabular}

Table 2. Demographic, clinical and neuropsychological data for participants with RHD and healthy control participants

\begin{tabular}{lccccccc}
\hline & \multicolumn{2}{c}{ RHD } & & \multicolumn{2}{c}{ Healthy control } & p-value \\
\cline { 2 - 3 } & Mean & SD & & Mean & SD & \\
\hline Age & 62.0 & 10.1 & & 61.35 & 10.7 & 0.844 \\
Educational level & 12.55 & 3.1 & & 12.4 & 2.7 & 0.871 \\
Gender (male/female) & $10 / 10$ & & & $11 / 9$ & & \\
Time post-onset (in months) & 76.3 & 75.6 & & & & \\
& & & & & & \\
Trail B (completion time) & 154.1 & 105.0 & & 84.45 & 33.8 & \\
Trail B/Trail A (time) & 2.7 & 1.3 & & 2.2 & 0.7 & 0.164 \\
WCST (categories) & 5.2 & 1.2 & & 5.1 & 1.6 & 0.736 \\
WCST (\% perseverative errors) & 37.4 & 20.1 & & 29.25 & 26.5 & 0.280 \\
Stroop (colors/words, time in s) & 37.5 & 10.8 & & 33.09 & 12.4 & 0.237 \\
Hayling (automatic condition) & 5.85 & 0.8 & & 6.15 & 0.4 & 0.141 \\
Hayling (inhibition condition) & 9.6 & 2.3 & & 11.5 & 1.8 & $\mathbf{0 . 0 0 6}$ \\
Digit span (forward) & 8.9 & 1.9 & & 9.5 & 2.33 & 0.379 \\
Digit span (backward) & 6.0 & 1.9 & & 5.8 & 1.4 & 0.703 \\
\hline
\end{tabular}


Table 3. Percentage of correct responses to the question on irony and to the control question in participants with RHD and healthy control participants

\begin{tabular}{lccccc}
\hline & \multicolumn{2}{c}{ RHD participants } & & \multicolumn{2}{c}{ HC participants } \\
\cline { 2 - 3 } \cline { 6 - 6 } & Mean (\%) & SD & & Mean (\%) & SD \\
\hline Question on irony & & & & & \\
Strong incongruity context condition & 72.5 & 36.1 & & 98.35 & 4.4 \\
Weak incongruity context condition & 61.3 & 33.8 & & 83.4 & 13.6 \\
No incongruity context condition & 94.7 & 9.0 & & 96.8 & 4.9 \\
\cline { 6 - 7 } Control question & & & & & \\
Strong incongruity context condition & 97.1 & 7.7 & & 97.6 & 4.7 \\
Weak incongruity context condition & 95.9 & 5.0 & & 97.6 & 4.9 \\
No incongruity context condition & 99.1 & 3.8 & & 98.0 & 3.6 \\
\hline
\end{tabular}

Table 4. Demographic, clinical and neuropsychological data for the healthy control (HC) group compared to participants with RHD with unimpaired (RHD-U) or impaired (RHD-I) irony comprehension

\begin{tabular}{|c|c|c|c|c|c|c|c|}
\hline & \multicolumn{2}{|c|}{ RHD-U } & \multicolumn{2}{|c|}{ RHD-I } & \multicolumn{2}{|c|}{ Healthy control } & \multirow[t]{2}{*}{$p$-value } \\
\hline & Mean & SD & Mean & SD & Mean & SD & \\
\hline Age & 62.79 & 12,0 & 60.17 & 5.7 & 61.35 & 10.7 & 0.690 \\
\hline Educational level & 13.07 & 3.5 & 11.33 & 1.5 & 12.4 & 2.7 & 0.385 \\
\hline Gender (male/female) & $8 / 6$ & & $2 / 4$ & & $11 / 9$ & & \\
\hline Time post-onset (in months) & 90.36 & 81.7 & 43.5 & 50.4 & & & 0.058 \\
\hline Trail B (completion time) & 178.79 & 116.8 & 96.33 & 28.9 & 84.45 & 33.8 & $0.005 \$$ \\
\hline Trail B/Trail A (time) & 107.14 & 78.8 & 55.33 & 33.0 & 45.36 & 28.4 & 0.628 \\
\hline WCST (categories) & 5.21 & 1.4 & 5.17 & 0.8 & 5.1 & 1.6 & 0.671 \\
\hline WCST (\% perseverative errors) & 40.21 & 19.4 & 30.83 & 22.0 & 29.25 & 26.5 & 0.210 \\
\hline Stroop (colors/words, time in s) & 38.07 & 10.7 & 36.17 & 11.8 & 33.09 & 12.4 & 0.255 \\
\hline Hayling (automatic condition) & 5.79 & 1.0 & 6.00 & 0,0 & 6.15 & 0.4 & 0.373 \\
\hline Hayling (inhibition condition) & 9.79 & 2.4 & 9.17 & 2.4 & 11.5 & 1.8 & $0.033 \$ !$ \\
\hline Digit span (forward) & 8.57 & 2.1 & 9.67 & 1.2 & 9.5 & 2.33 & 0.383 \\
\hline Digit span (backward) & 6.0 & 2.1 & 6.0 & 1.1 & 5.8 & 1.4 & 0.957 \\
\hline
\end{tabular}

Legend: The symbols * and \$ indicate significant differences between the groups with \$ HC $\neq$ RHD-U; ! HC $\neq$ RHD-I 
Figure 1. Dendrogram using Ward's method on the RHD group (20 observations).

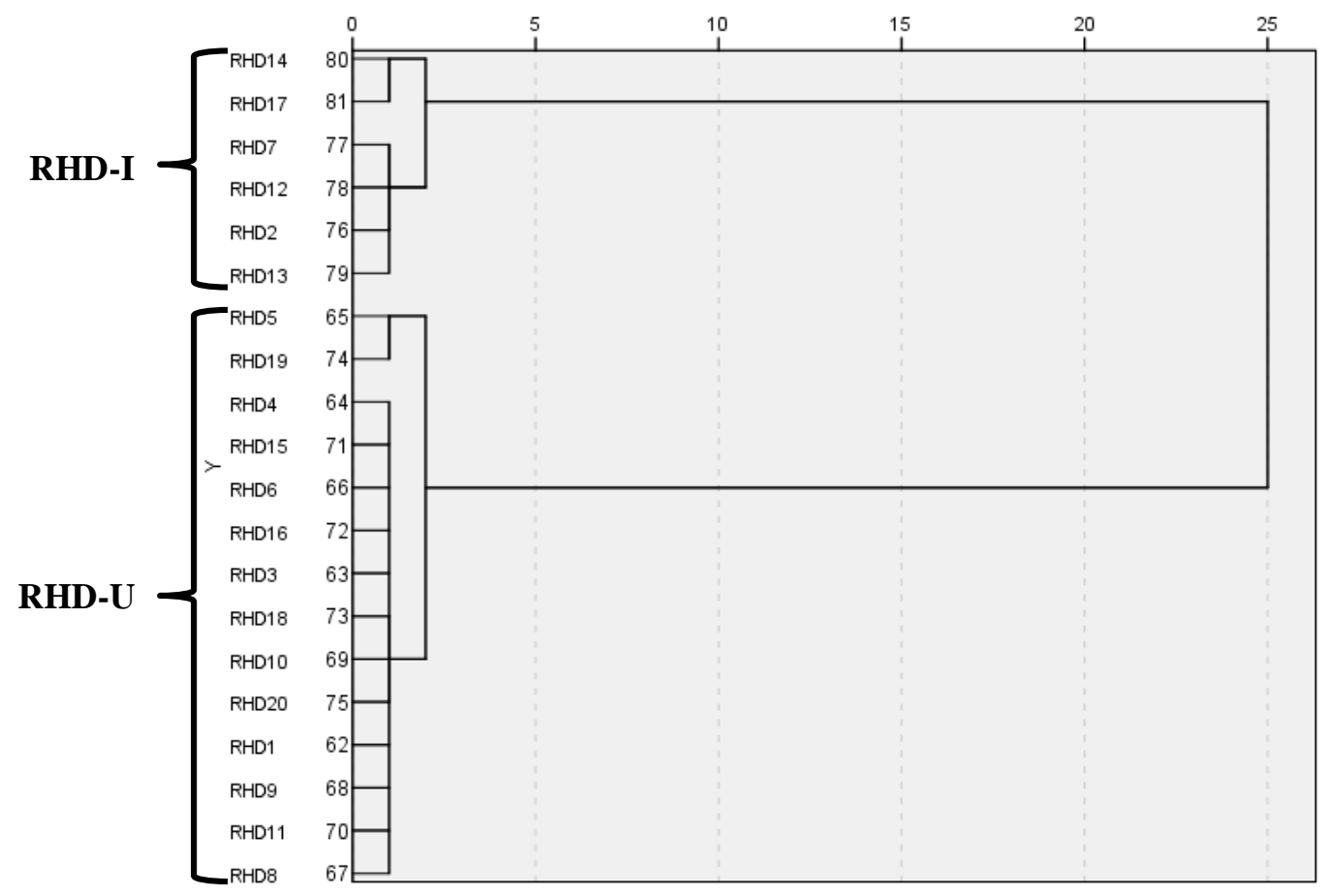

Legend: Each participant with RHD represents a line on the ordinate axis of the figure. RHDU: participants with RHD unimpaired in irony understanding; RHD-I: participants with RHD impaired in irony understanding.

Figure 2. Percentage of correct responses to the question on speaker's ironic intent for the healthy control (HC) participants compared to participants with RHD with unimpaired (RHDU) or impaired (RHD-I) irony comprehension

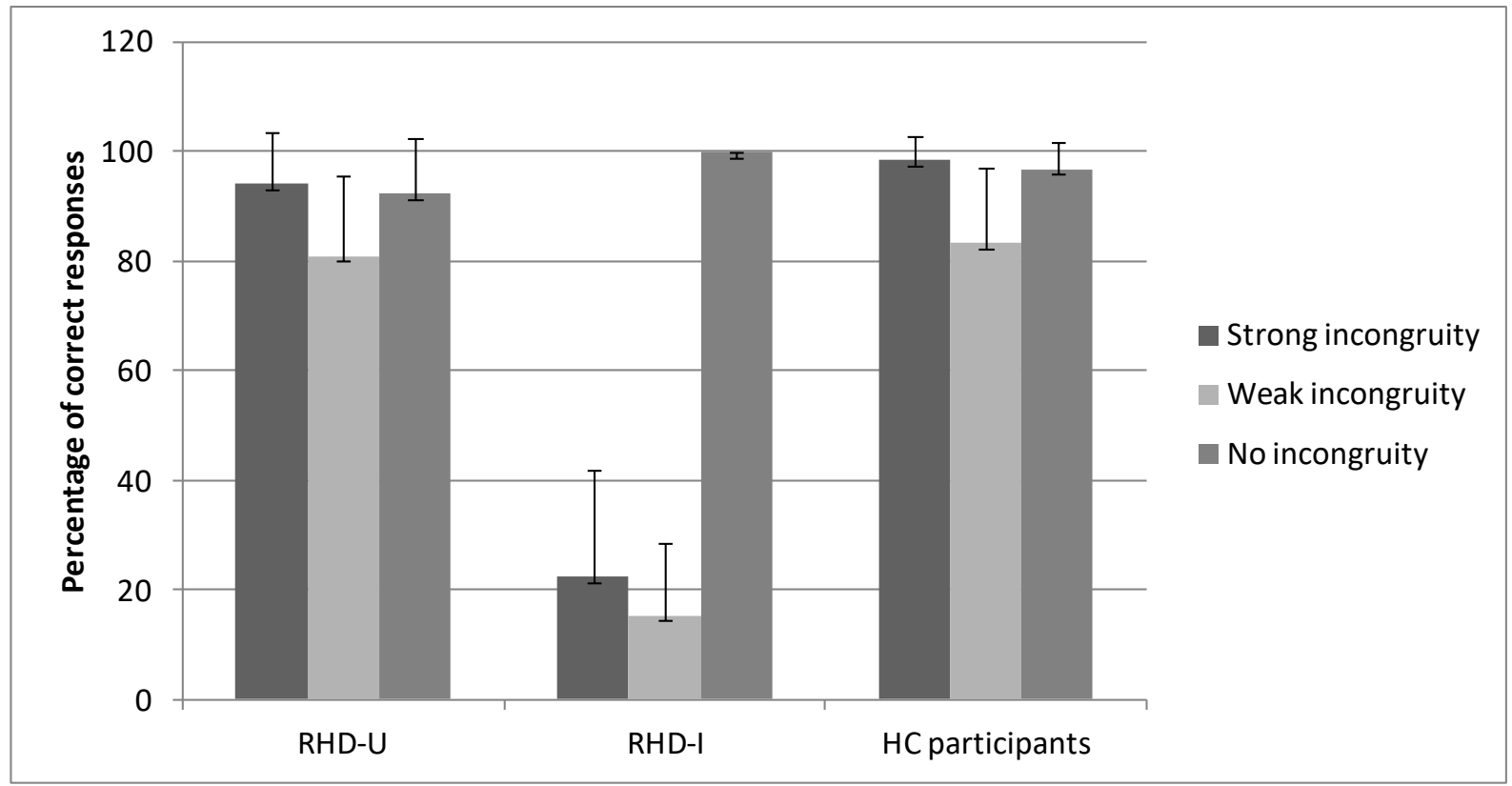


Figure 3. Percentage of correct responses to the control question for the healthy control (HC) participants compared to participants with RHD with unimpaired (RHD-U) or impaired (RHD-I) irony comprehension

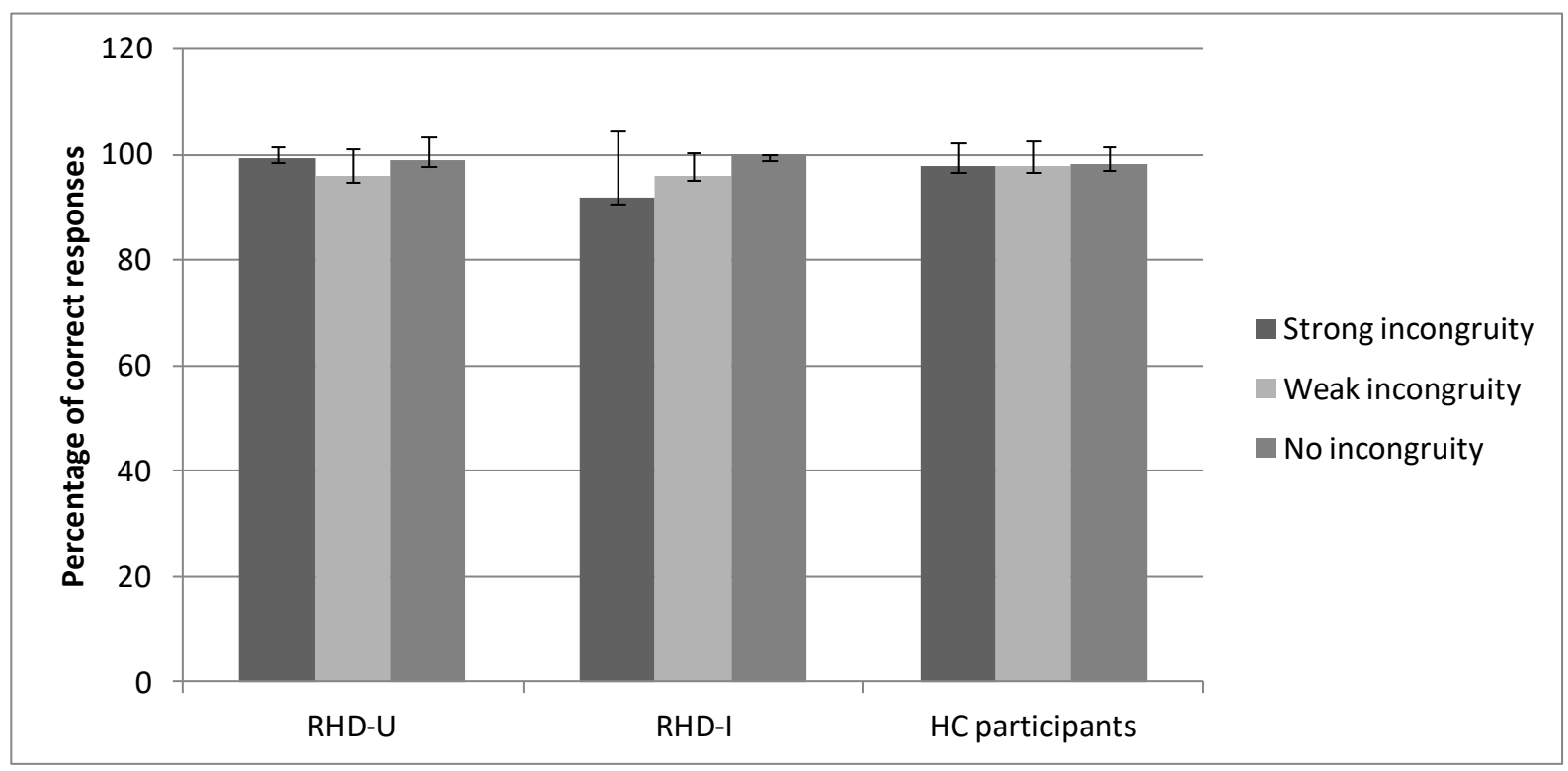

